\title{
Selfevidensie in die Natuurwetenskap
}

\section{Wetenskapsleer van Aristoteles.1)}

Die hoofpunte van Aristoteles se wetenskapsleer kan saamgevat word in die vorm van 'n definisie van "deduktiewe wetenskap".

'n Deduktiewe wetenskap is ' $n$ stelsel of versameling $W$ van beweringe sodanig dat:

1. Alle beweringe van $W$ betrekking het op één gebied van werklike objekte.

2. Alle beweringe van $W$ waar is.

3. Indien sekere beweringe tot $\mathrm{W}$ behoort, ook elke logiese gevolgtrekking uit die beweringe tot $\mathrm{W}$ hoort.

4. Daar in $W$ 'n eindige aantal terme aan te wyse is sodanig dat:

a. die betekenis van die terme geen nadere verklaring nodig het nie-die sg. ongedefinieerde terme of grondbegrippe;

b. die betekenis van alle ander terme wat in $\mathrm{W}$ optree met behulp van hierdie terme omskryf kan word.

5. Daar in $W$ ' $n$ eindige aantal beweringe (aksiomas) aan te wyse is sodanig dat

a. die waarheid van hierdie beweringe evident is;

b. alle ander beweringe van $W$ uit hierdie beweringe langs deduktiewe weg te verkry is.

Wat ons in hierdie artikel interesseer, is veral die sg. evidensie-postulaat soos gestel in 4a en 5a. Hiervan sê Aristoteles2): ..Dit is noodsaaklik dat 
mens die grondstellinge, hetsy almal, hetsy enkele daarvan, nie slegs eerder, maar ook beter ken ..... ; dit is noodsaaklik dat daar meer geloof geheg word aan die beginsels, as aan die konklusie daaruit".

Daar moet op gewys word, veral met die oog op die beskouinge hierna, dat die wetenskapsleer van Aristoteles bedoel was om die grondslag te vorm en die metode te gee veral vir die fisika. Die bostaande uitspraak van Aristoteles het dan ook betrekking op aksiomas i.v.m. objekte uit die materiële werklikheid (vgl. postulaat 1).

Bostaande gesketste wetenskapsleer moes Aristoteles noodsaaklik bring tot die opstel van 'n metafisika in die sin van 'n grondslae-ondersoek van die wetenskap en in die besonder van die fisika, en nie in die sin waarin die term metafisika vandag meestal gebruik word nie nl. die leer van die bo-sinlike in teëstelling tot die fisika as die leer van die sintuiglik-waarneembare.

Ook die kennisteorie, as leer van die oorsprong van ons kennis, sou as gevolg van hierdie wetenskapsleer onder die soeklig kom, want as al ons wetenskaplike kennis verkry word langs deduktiewe weg uit sekere onherleibare begrippe en aksiomas, dan doen die vraag homself voor hoe die mens aan hierdie begrippe en aksiomas kom. Hieroor laat Aristoteles hom soos volg uit2): ,Dit is duidelik dat ons die grondstellinge noodsaaklikerwys deur induksie ken; immers, die sintuiglike waarneming verskaf ons op hierdie wyse ook die algemene (t.w. die ,,begrippe”). Daar van die geestesvermoëns, wat betrekking het op ons denke, sommige altyd waar is, andere ons ewewel die onware voorspieël soos die mening en die redenering (uit nie-evidente premisse)-die deduktiewe wetenskap en die intuïsie is egter altyd waar-en aangesien geen vorm van kennis eksakter is as die deduktiewe wetenskap nie, of dit moet die intuïsie wees, daar verder die grondstellinge beter bekend is as die afgeleide stellinge, en daar, ten slotte, die hele deduktiewe wetenskap deur logiese redenering verkry word, kan daar geen deduktiewe fundering van die grondstellinge gegee word nie; aangesien daar verder niks meer waar is as die deduktiewe wetenskap, behalwe die intuïsie nie, moet daar intuïtiewe insig bestaan omtrent die grondstellinge, en uit hierdie oorweging volg ook dat die grondslag van 'n deduktiewe wetenskap geen deduktiewe wetenskap kan wees nie. Maar as ons naas die deduktiewe wetenskap niks waars het behalwe die intuïsie nie, dan moet die intuïsie die grondslag van die deduktiewe wetenskap wees".

Hierdie opvatting van Aristoteles berus op sy oortuiging dat die sintuiglik-waarneembare verskynsels manifestasies is van 'n met rede begaafde wese en dat die mens tot hierdie wese in 'n betrekking van verwantskap staan. Daarom is die mens in staat om by die waarneem van verskynsels hulle 
diepste gronde intuittief te ondersoek. Dit is die induksie in die sin van Aristoteles waardeur insig in beginsels tot stand kom.

Beth beweer dan verder3): „De beginselen van de deductieve wetenschappen behoeven dan ook niet door middel van opzettelijk en stelselmatig onderzoek te worden opgespoord: een zeer summiere kennisneming van de verschijnselen is voldoende, om ze ons tot bewustzijn te brengen. De kennis van de beginselen is bijgevolg geen monopolie van den philosoof; ze is eigen aan elken mensch." Tot sover dan Aristoteles oor die selfevidensie van beginsels volgens Beth.

Uit bostaande blyk die groot mate van vertroue in die warheid van intuitiewe insigte deur Aristoteles. Vir hom is die intuïsie die kenfunksie wat ons die uiteindelike grondwaarhede van alle dinge laat ken. Dit is bekend dat die wiskunde en in die besonder die meetkunde (euklidies) as model gedien het van 'n deduktiewe wetenskap by die opstel van sy wetenskapsleer. Die begrippe en stellinge van die ruimteleer, soos opgebou deur Euklides en sy voorgangers, sou nou tot dié elemente van ons kennis behoort wat ons deur ons intuïsie met sekerheid uit die gegewens van ons sintuiglike waarneming kan aflees. In die besonder besit die aksiomas en ongedefinieerde begrippe van die euklidiese meetkunde, op grond van hulle int uitiewe aard, volkome sekerheid en kan deur geen enkele empiriese gegewe weerspreek word nie4).

Tot hierdie intuïtief-kenbare beginsels word ook bv. gereken die grondbegrippe en grondstellinge van die logika en ook die kousaliteitswet.

Vreemd genoeg was dit weer die wiskunde en by name die meetkunde, wat dié deel van Aristoteles se wetenskapsleer op losse skroewe gesit het. As gevolg van die ondersoekinge van Lobatschewsky, Riemann en Gauss in die vorige eeu, wat in die volgende paragraaf kortliks bespreek sal word, is daar aan die volkome sekerheid van die aksiomas van die euklidiese meetkunde, as stellings wat ons 'n ware beeld van die fisiese ruimte gee, begin twyfel.

Die opvatting egter, dat die wetenskap op bepaalde grondbegrippe en grondstellinge berus wat op geen wyse deur wetenskaplike ondersoek aangetas of selfs gewysig kan word nie, is altyd in sommige wetenskaplike kringe gehuldig, veral in filosofiese kringe. By byna alle filosofiese denkrigtinge word daar ' $n$ beroep gedoen op die intü̈sie vir die ken en sekerheid van hulle beginsels. Die gryp van selfevidente beginsels op grond van intuisie is deel van die fenomonologiese metode in die wysbegeerte. Die volgende aanhaling i.v.m. intuïsie as kenfunksie hou daarmee verband: „'n Intuïsie (beginselinsig) is ' $n$ aanskouing, 'n sien met die verstandsoog. Dit is 'n 
onmiddellike insig waarby meteen onmiddellik die geldigheid, die waarheid, van die intuisie ingesien word. Die intuïtiewe insig is ook onmiddellik in die sin dat die insig verkry word sonder tussenkoms van bewyse, dit vind sy begronding in homself. Die intuisie (d.w.s. die beginsel) is selfevident; dit getuig self van sy eie waarheid; dit openbaar homself in sy eie geldigheid. Die intuisie (d.w.s. die beginsel) is outopisties; dit is selfgeloofwaardig; dit getuig self van sy anneembaarheid en geloofwaardigheid. Vir die een wat ' $n$ beginsel intuïtief insien, bied die intuisie (die beginsel) sy eie sekerheid, versekerdheid, onbetwyfelbaarheid"s).

Die mate waarmee intuitiewe insigte as waar beskou is deur Kant. blyk uit die volgende twee anhalings: „Solche allgemeine Erkenntnisse nun, die zugleich den Charakter der innern Notwendigkeit haben, müssen .... . vor sich selbst klar und gewiss sein; man nennt sie daher Erkentnisse a priori....." Ook ken hy an die aksiomas van die euklidiese meetkunde volkome sekerheid toe: „die geometrischen Sătze suid insgesamt apodiktisch, d.i. mit dem Bewusstsein ihrer Notwendigkeit verbunden"6).

Hy vereenselwig hom egter nie met die verklaring wat Aristoteles gee vir die apodiktiese sekerheid van die aksiomas nie.

In die filósofie van Bergson speel die intuïsie 'n oorheersende rol. Hy skryf: ...(There are) two profoundly different ways of knowing a thing. The first implies that we move round the object: the second that we enter into it. The first depends on the point of view at which we are placed and on the symbols by which we express ourselves. The second neither depends on a point of view nor relies on any symbol. The first kind of knowledge may be said to stop at the relative: the second, in those cases where it is possible. to attain the absolute" 7 ). Hierdie tweede maniere dan is deur intuïsie. Duidelikheidshalwe moet gesê word dat intuisie soos by Bergson en intuisie by Aristoteles nie dieselfde is nie. Albei beroep hulle egter op elfevidensies waar dit op die waarheid van die intuïtiewe insigte aankom.

Deur die ontstaan van die nie-euklidiese meetkundes van Lobatschewsky en Riemann en deur ander verwikkelings in die natuurwetenskappe, is ons vandag egter gedwing om bostaande beskouings besonder krities te beskou. Beth beweer selfs:

,Met de verwerping of de aanvaarding van het legitiem wetenschappelijk karakter van de niet-euclidische stelsels staat of valt Aristoteles' methodologie der deductieve wetenschappen; maar de vraag naar de houdbaarheid van deze methodologie is een vraag van zijn of niet zijn voor de systematische wijsbegeerte. zoals deze sinds ruim tweeduizend jaar is beoe- 
fend"8). In hoeverre die laaste deel van hierdie stelling geld, sou skrywer van hierdie artikel nie kon beoordeel nie. Dat die grond waarop Aristoteles sy wetenskapsleer stel, deur verskillende filosowe in een of ander vorm gehandhaaf word, blyk voldoende uit bostaande aanhalings.

Die beskouing van die meeste hedendaagse natuurwetenskaplikes en wiskundiges is dat die wetenskap inderdaad van sekere a priori's, gegrond op die intuïsie, moet uitgaan, maar hulle betwis die selfgeloofwaardigheid, die onbetwyfelbare waarheid van hierdie a priori's, met enkele uitsonderinge. Klein skryf bv.: „.... the naive intuition is not exact, while the refined intuition is not properly intuition at all, but arises from the development from axioms considered as perfectly exact."9)

Dat selfevidensie nie heeltemal uit die kennisteorie geban kan word nie, is duidelik as daaraan gedink word dat dit selfevidensie is wat ons die logiese argument laat aksepteer dat, as alle mense sterfik is en Socrates is 'n mens, dan is Socrates sterflik.

Die verset van natuurwetenskaplikes is dan ook eintlik dáárteen gerig dat te veel beginsels as selfevident beskou is; dat te maklik op absolute sekerheid van intuittiewe insigte aanspraak gemaak word en hulle ontken dat die empirie nie die sg. selfevidente beginsels sou kon wysig nie. Russel beweer: „If, however, self-evidence is to be accepted as a guarantee of truth, the concept must be carefully distinguished from others that have a subjective resemblance to it. 1 think we must bear it in mind as relevant to the definition of "knowledge", but as not in itself sufficient"10).

Hoe beskou die wiskundiges dan die ,waarheid" van die aksiomas van bv. die meetkunde? In die wiskunde word onderskeid gemaak tussen die aksiomas as nie-strydige formele uitsprake en die betrekking wat hierdie aksiomas het t.o.v. die werklikheid buite die gedagtewêreld van die matematikus. Die aksiomas hoef nl. nie waar te wees in die sin dat hulle in ooreenstemming moet wees met die werklikheid waaroor die aksiomas pleeg uitspraak te gee nie. Die enigste eis wat die wiskundige aan die aksiomas stel, is dat hulle nie-strydig moet wees, d.w.s. dat dit nie moontlik moet wees om 'n stelling en dié se teëgestelde uit dieselfde stel aksiomas af te lei nie. Die eis is dus: nie-strydigheid van die aksiomas en waarheid van die gevolgtrekkinge in die sin van geldigheid m.b.t. die aksiomas, d.w.s. die gevolgtrekkinge moet logies uit die aksiomas en slegs uit die aksiomas afleibaar wees. So word nie in die wiskunde anspraak daarop gemaak dat die aksiomas en stellinge van die meetkunde ons ' $n$ ware beeld van die fisiese ruimte 
gee nie-wat vir die wiskundige van belang is, is slegs dat die aksiomas niestrydig is en die stellinge geldig moet wees m.b.t. die aksiomas.

Ook die grondbegrippe van die wiskunde word beskou as nie identifiseerbaar met dinge in die werklikheid buite ons denke nie maar bloot as gedagtekonstruksies, weliswaar geabstraheer uit die werklikheid maar sonder teëhangers in die werklikheid. So word bv. punt, reguit lyn en ruimte in die meetkunde beskou as gedagtekonstruksies sonder teëhangers in die fisiese werklikheid. Die wiskundige gaan selfs nog verder. Hy vervang die grondbegrippe met simbole waaraan hy geen bepaalde betekenis toeken nie. Die aksiomas word dan beweringe wat betrekking het op hierdie simbole en die stellings is logiese gevolgtrekkings uit hierdie basiese beweringe. As aan die simbole later betekenisse toegeken word. sodat die aksiomas sinvolle uitsprake is, is die stellinge (gevolgtrekkings) ook sinvolle beweringe omtrent die dinge waarop die resulterende terme dan betrekking het. So kan ' $n$ bepaalde stelling meer as een interpretasie hê. Algemeen bekend is die duale opbou van die meetkunde waar bv. in elke stelling ' $n$ bepaalde simbool met „punt" of met "reguit lyn" vervang kan word en die resultaat in elke geval ' $n$ sinvolle geldige stelling word. Die leser sal begryp waarom Einstein beweer: ,.As far as the propositions of mathematics refer to reality they are not certain, and in so far as they are certain they do not refer to reality."11) Die eksaktheid van die wiskunde het slegs betrekking op die geldigheid van stellinge (gevolgtrekkinge) m.b.t. die aksiomas en het nie betrekking op die waarheid van die stellinge m.b.t. die werklikheid nie.

Vanuit die wiskunde het hierdie beskouinge ook deurgewerk na die fisici en hulle opvatting aangaande grondbegrippe en a priori's van die fisika. Ook deur baie fisici word dit betwis dat die grondbegrippe van die fisika noodwendig teëhangers het in die fisiese werklikheid en dat die a priori's van die fisika onbetwyfelbaar waar is. Aangesien in die fisika egter beweringe gedoen word en uitsprake gegee word i.v.m. dinge in die werklikheid buite ons gedagtewereld, kan die fisici nie soos die wiskundiges ewe gerieflik die band tussen aksiomas en werklikheid breek nie en hulle wil ook nie vir die uitsprake van die fisika alleen aanspraak maak op waarheid in die sin van geldigheid t.o.v. hulle aksiomas nie. Uit hierdie dilemma red hulle hulself deur hulle te beroep op die empirie. Elke gevolgtrekking gedoen uit die a priori's. postulate of hipoteses, moet vir sover moontlik eksperimenteel getoets word. om daarmee die gevolgtrekking se ooreenstemming met die werklikheid na te gaan. Bowendien geld, nes in die wiskunde, die eis van geldigheid van die gevolgtrekking t.o.v. die aksiomas en die nie-strydigheid van die aksiomas. Stem die eksperiment nie ooreen met 'n 
bepaalde gevolgtrekking uit die aksiomas nie, word nuwe aksiomas ingevoer om die saak so te probeer verbeter. Hierdie nuwe aksiomas is dan gewoonlik ook nie meer selfevidente, intuïtiewe insigte nie (is gewoonlik alles behalwe selfevident) en kan bv. eksperimentele feite wees.

'n Gevolg van hierdie standpunt is dat die moderne fisika neig om aan sommige aksiomas en grondbegrippe geen ander waarde toe te ken nie as 'n beskrywende waarde. Om bv. te sê dat 'n elektron 'n massadeeltjie is, beteken dan niks meer nie as om te sê dat 'n elektron se gedrag in sekere omstandighede baie ooreenkom met die van 'n albaster. In ekstreme gevalle word selfs die kousaliteitswet gereduseer tot 'n beskrywing van sekere reekse gebeure in die werklikheid.

Daar die geloofwaardigheid van die intuîtiewe a priori's en grondbegrippe in twyfel getrek word, word die taak van die fisika gevolglik beskou, nie soseer om die diepste aard (die wese) van materie en verskynsels verbonde aan materie bloot te lê nie, maar om waargenoem verskynsels m.b.v. abstrakte begrippe en bepaalde aksiomas te korreleer, d.w.s. om met behulp van begrippe en aksiomas verbande te lê tussen die verskynsels.12)

Wat die aanleidende oorsake van hierdie standpunt by natuurwetenskaplikes was, sal kortliks in die volgende paragraaf geskets word.

\section{Nie-euklidiese meetkundes en relatiwiteit.}

Die grondbegrippe van die euklidiese meetkunde, wat nie gedefinieer kan word sonder om in ' $n$ regressus in infinitum of ' $n$ circulus in probando (c.q. in definiendo) te verval nie, is o.a. punt, reguit lyn, vlak en ruimte. Die aksiomas van die euklidiese meetkunde omvat o.a.:

1. Twee van mekaar verskillende punte A en B bepaal steeds 'n reguit lyn a;

2. op 'n reguit lyn lê steeds minstens twee punte en in 'n vlak lê steeds minstens drie punte wat nie op 'n reguit lyn lê nie;

3. 'n vlak word deur drie punte op die vlak bepaal mits hulle nie op 'n reguit lyn lê nie;

4. as A, B. C punte van 'n reguit lyn is, en B lê tussen $A$ en $C$, dan lê $B$ ook tussen $C$ en $A$;

en so ' $n$ hele aantal meer. Die paar aksiomas is neergeskryf om die leser te oortuig dat die aksiomas van die euklidiese meetkunde, by eerste kennismaking. inderdaad as selfevident en volkome geloofwaardig beskou kan wosd. 
Die aksioma wat die middelpunt van die volgende betoog sal vorm, is die volgende:

5. Laat a ' $n$ willekeurige reguit lyn en $A$ ' $n$ punt, nie op a nie, wees, dan is daar in die vlak deur a en $A$ een en slegs een reguit lyn wat deur A gaan en a nie sny nie.

Hierdie aksioma van parallelisme was deur Euclides oorspronklik in 'n enigsins ander vorm, as die vyfde postulaat in sy boek gestel. Hierdie aksioma kan nie met reg op aanskoulikheid aanspraak maak nie, aangesien dan 'n lynstuk wat onbepaald na albei kante verleng is, as aanskoulik beskou moet word.

Die vyfde aksioma van Euclides is deur die eeue heen met wantroue deur wiskundiges beskou, daar hulle gemeen het dat dit moontlik as 'n stelling uit die ander aksiomas afgelei kan word. Die taak is o.a. deur die priester Saccheri aangepak wat die stelling probeer bewys het uit die ongerymde. Deur aan te neem dat deur' $n$ punt buite 'n reguit lyn minstens twee reguit lyne getrek kan word parallel aan die eerste (d.w.s. twee reguit lyne wat die eerste nie sny nie), het hy gehoop om in teěspraak te kom met die ander aksiomas. Stelling na stelling is deur hom afgelei sonder om die gewenste teëspraak te vind. Vandag staan dit vas dat daar geen teëspraak kan ontwikkel nie, omdat die vyfde postulaat onafhanklik is van die ander aksiomas.

Deur Lobatschewsky is ingesien dat, deur die vyfde postulaat van Euclides te vervang met die reeds genoemde postulaat van Saccheri, 'n meetkunde opgebou kan word wat net soos die euklidiese meetkunde op niestrydigheid kan aanspraak maak. Deur hom is die sg. hiperboliese meetkunde op dié wyse opgebou.

Deur Riemann is die vyfde postulaat vervang deur die volgende: deur 'n punt buite 'n reguit lyn kan geen enkele reguit lyn parallel aan die eerste getrek word nie. Deur hom is die sg. elliptiese meetkunde opgebou wat ook op nie-strydigheid kan aanspraak maak.

Dat die resultate van die drie meetkundes sal verskil, is duidelik. So is die som van die drie hoeke van 'n driehoek in die hiperboliese meetkunde kleiner as twee regte hoeke, in die euklidiese meetkunde gelyk aan twee regte hoeke en in die elliptiese meetkunde groter as twee regte hoeke.

Die beswaar van onaanskoulikheid deel die postulate van Lobatschewsky en Riemann met dié van Euclides-vir sommige mense is die beswaar egter groter by e.g. twee. 
Tussen die drie meetkundes, as logiese strukture gegrond op bepaalde begrippe en aksiomas, is nie te kiese nie, en t.o.v. hulle aksiomas is die een so geldig soos die ander. Watter een van die drie gee om nou 'n juiste beeld van die fisiese ruimte? In sy relatiwiteitsteorie het Einstein die elliptiese meetkunde toegepas op 'n vierdimensionale kontinuum van ruimte en tyd met uitstekende resultate. Nie alleen het hy daarin geslaag om verskynsels daarmee te verklaar wat om verklaring gewag het nie, maar het hy ook verskynsels voorspel wat later eksperimenteel geverifieer is.

In beginsel is dit moontlik om eksperimenteel vas te stel watter meetkunde op die fisiese ruimte van toepassing is, mits natuurlik aan die ander postulate i.v.m. fisiese verskynsels vasgehou word. As ons aanneem dat lig reglynig voortgeplant word. d.w.s. dat die baan van 'n ligstraal ooreenstem met ons intuítiewe begrip reguit lyn, en dit sou moontlik wees om die drie hoeke van 'n driehoek. waarvan die hoekpunte drie sterre is, te meet. dan sal bv. die elliptiese meetkunde geldig wees vir die fisiese ruimte as gevind word dat, met inagneming van eksperimentele foute, die som van die hoeke groter is as twee regte hoeke. In dié geval kan egter met ewe groot reg aan die euklidiese meetkunde vasgehou word en gekonkludeer word dat ligstrale hulle nie reglynig voortplant nie. Veral Poincaré(3) het daarop gewys dat beide gesigspunte, mits konsekwent volgehou, houdbaar is. Die grondslag van die meetkunde, as beskrywing van die eienskappe van die fisiese ruimte. is konvensioneel. Watter konvensie in 'n konkrete geval gekies word. hang af van die praktiese konsekwensies; teoreties staan die wetenskaplike vry. Opvallend is dit dat Poincare die vashouding van die euklidiese meetkunde as ,plus commode” beskou, terwyl in die moderne fisika die elliptiese meetkunde voorkeur geniet. Dat die fisika hier heeltemal afstand gedoen het van die selfgeloofwaardigheid en waarheid van intuîtiewe insigte. is uit die betoog duidelik.

'n Ander duidelike voorbeeld waar afstand gedoen is van die waarheid van intuitiewe insigte in die fisika, is in die spesiale relatiwiteitsteorie van Einstein. Dit moet as selfevident beskou word dat as twee voorwerpe A en $B$ in ' $n$ reguit lyn beweeg met snelhede $u$ en $v$ t.o.v. die aarde, dan sal die relatiewe snelheid van A t.o.v. B u plus $v$ wees as hulle in teëgestelde rigtings beweeg en $u$ minus $v$ as hulle in dieselfde rigting beweeg. Ook lig word met 'n bepaalde snelheid voortgeplant. Dit is natuurlik om hierdie snelheid met die fisiese ruimte as absolute agtergrond te sien. Dan sal mens verwag dat die snelheid van lig verskillend moet wees vir waarnemers op verskillende bewegende voorwerpe. Deur Michelson en Morley is eksperimenteel vas- 
gestel dat die spoed van lig vir alle waarnemers dieselfde bly ongeag die spoed van die voorwerp waarop die waarnemer hom bevind-as vasgehou word aan die ander postulate wat betrekking het op die geval. Hierdie allermins selfevidente eksperimentele feit is deur Einstein as postulaat in sy spesiale relatiwiteitsteorie gebruik, en daarmee het hy skitterende resultate behaal.

Die slotsom van dit alles word deur Beth so gestel: „Niet alleen hebben de niet-euclidische stelsels zich een blijvende plaats veroverd in de wiskunde en is haar waarde ook voor de natuurwetenschap op overtuigende wijze gebleken, naast deze stelsels sijn bovendien andere wiskundige en natuurwetenschappelijke theorieën ontstaan, welker aanvaarding evenmin te rijmen valt met het vasthouden aan Aristoteles' wetenschapsleer"14).

Die vraag kom nou na vore of dit moontlik is om 'n wetenskap te bou op bepaalde vooraf-aanvaarde beginsels, as beginsels dan deur die ervaring of empirie gewysig kan word. Dat beginsels wat berus op intuïtiewe insig nie altyd volle sekerheid het nie, moet m.i. toegegee word. Dat 'n wetenskap sonder a priori's opgebou kan word, slegs deur voortdurend beroep op die empirie te doen, lyk ook onmoontlik. Dat bepaalde a priori's gewysig kan word deur die ervaring, moet egter m.i. toegegee word. Die vraag is in hoeverre alle a priori's wysigbaar deur die ervaring is. M.i. word in die natuurwetenskappe en in die wysbegeerte nie voldoende onderskeiding gemaak tussen aksiomas of postulate, hipoteses en beginsels nie. As beginsels moet $\mathrm{m}$. i. slegs daardie vooropstellinge gereken word waarsonder geen opbou van enige wetenskap moontlik is nie en dié wat vanweë hulle aard nooit dwingend deur die ervaring aangetas kan word nie. Wat hulle is, is die taak van sowel die filosoof as die vakwetenskaplike om na te gaan. Alleen as daar duidelikheid oor hierdie vrae bestaan, kan daar op 'n vaste fondament voortgebou word.

\section{H. J. SCHUTTE}

1) Para. 1 is gebaseer op hoofstuk 1 van (1).

2) Soos aangehaal deur E. W. Beth in hoofstuk 1 van (1).

3) (1) p. 14.

4) (2) p. 111 .

5) Met verlof van prof. H. G. Stoker aangehaal uit 'n ongepubliseerde diktaat.

6) Aangehaal deur Beth in (2) p. 111.

7) Aangehaal deur B. Russel in (5) p. 14.

8) (2) p. 34.

9) Soos aangehaal deur E. W. Beth in (2) p. 29.

10) (4) p. 172. 
11) Soos aangehaal deur $H$. Weyl in (7), p. 134.

12) Vgl. H. J. Schutte; Oor die begrip wese, Koers, April 1955.

13) H. Poincaré: (3).

14) (2) p. 34

(1) E. W. Beth: Wijsbegeerte der Wiskunde. Antwerpen 1950.

(2) E. W. Beth: Wijsgerige ruimteleer. Antwerpen 1950.

(3) H. Poincaré: Science et méthode. Paris 1908.

(4) B. Russel: Human Knowledge. Londen 1948.

(5) B. Russel: Mysticism and Logic and other Essays. Londen 1950.

(6) E. R. Stabler: An Introduction to Mathematical Thought. Cambridge, Mass. 1953.

(7) H. Weyl: Philosophy of Mathematics and Natural Science. Princeton 1949. 